\title{
Scrum Methodology in Higher Education: Innovation in Teaching, Learning and Assessment
}

\author{
Antonio Jurado-Navas ${ }^{1} \&$ Rosa Munoz-Luna ${ }^{2}$ \\ ${ }^{1}$ Dpt. Ingeniería de Comunicaciones, University of Málaga, Campus Teatinos s/n, E-29071 Málaga, Spain \\ ${ }^{2}$ Dpt. Filología Inglesa, Francesa y Alemana, University of Málaga, Campus Teatinos s/n, E-29071 Málaga, Spain \\ Correspondence: Antonio Jurado-Navas, Dpt. Ingeniería de Comunicaciones, University of Málaga, Campus \\ Teatinos s/n, E-29071 Málaga, Spain
}

Received: October 13, 2017

Accepted: November 2, 2017

Online Published: November 7, 2017

doi:10.5430/ijhe.v6n6p1

URL: https://doi.org/10.5430/ijhe.v6n6p1

\begin{abstract}
The present paper aims to detail the experience developed in a classroom of English Studies from the Spanish University of Málaga, where an alternative project-based learning methodology has been implemented. Such methodology is inspired by scrum sessions widely extended in technological companies where staff members work in teams and are assigned tasks within long-termed projects. Students were initially reluctant and afraid to work in teams but, as the experience advanced, their point of view was changing. Thus they positively stated that this methodology encouraged themselves to participate and to change ideas, with a deeper feeling of empathy, self-organisation and self-knowledge. At the end, most of the students declared they would participate again in a similar activity. Hence, considering the opinions from the students (and also from the teachers), and after observing the whole experience and analyzing the documents generated in an electronic portfolio, we think this method can be considered as a good proposal to accomplish a teaching-learning process of high quality at universities for three main reasons: first, it improves the capacity of using the knowledge in a disciplined, critical and creative way; second, it promotes the coexistence in heterogeneous human groups; and third, it develops the capacity of thinking, living and acting with complete autonomy.
\end{abstract}

Keywords: Scrum methodology, Teaching-learning process, Scrum master, Team, Product owner, Sprint, Self-organisation, Portfolio

\section{Introduction. Scrum Methodology: Bridging the Gap between Academia and the Business World}

The inspiration for this project arises from our own profesional experience in a technological company, namely Ericsson. In such a highly competitive working environment, it was crucial to organise working group projects efficiently. In fact, each developing group member must interact by following a particular manner of organisation (so-called self-organisation): the scrum methodology. The ultimate purpose of this working methodology was to follow an agile and effective procedure.

A parallel methodology in the context of Higher Education could be useful for students to invest quality working time in solving a project. Each student would be fully involved in the process according to their capabilities and potential. In particular, the scrum methodology is much more than group-work. Hence, we promote students to work following their personal interests. The topic that must be worked on is completely opened. Hardly a single sentence without any other instruction is provided to the students. That's all what students have to work. There is no small questions to guide the students neither steps to break down the project. On the contrary, they must manage to solve the problem in a self-organising manner taking into account the opinions and knowledge of the whole team. They are completely free to design the route map and to choose which type of final product they want to deliver. The topic is open, and many solutions can be offered if they are justified with appropriate criteria. And, finally, we want to familiarize students with their near work future.

Therefore, the aim of this paper is twofold: firstly, to propose in the academic world, and more specifically, at university, an alternative methodology for groupwork (scrum) in which students can learn to self-manage their time and resources for meaningful learning. Secondly, to observe and understand the transposing of business elements to an academic environment, bridging the existing gap between the two worlds. These broad aims contain more specific 
research objectives that will be detailed below.

Industry and university are aimed at providing mutual feedback and human resources. Both institutions working cooperatively would guarantee a labour market which is socially and culturally adapted to the students' needs, and an academic sector that responds to the demands of the business world.

An additional remarkable point in this paper is the fact that we have developed this alternative framework for learning in a Humanities course. Since the scrum methodology is extended in engineering companies, we thought that the adaptation in a Technical School would have been more straightforward than in a Humanities Faculty. For this reason, we implemented this scrum-based learning experience in the degree of English Studies at the University of Málaga, during the 2014-2015 academic year. To the best of our knowledge, this is the first report of a real scrum experience in a Philology degree.

\section{Theoretical Framework. State of the Art}

We highlight three theoretical pillars upon which scrum methodology is based: (i) university teaching innovation; (ii) social constructivism; and (iii) project based learning. The three suppositions allow for an agile methodology which is innovative and socially constructed (Vygotsky, 2012). The observation of the application of the scrum methodology in a university classroom will inevitably lead us to teaching innovation, something which deserves particular attention even out of the Faculties of Education. Innovating implies caring about students, contents and procedures.

\subsection{University Teaching Innovation}

In the field of university teaching innovation, some pedagogical efforts towards innovation are worth of mention: e-learning (Tavangarian, Leypold, Nölting \& Röser, 2004), blended learning or b-learning (Bartolomé, 2004) and mobile electronic learning or m-learning (Crompton, 2013). In the first modality, learning is online via Internet, this being an utterly virtual training which develops autonomous learning. B-learning, on its part, refers to semi-online learning, that is, a mixed option combining e-learning strategies and traditional face-to-face training. B-learning can also include m-learning, developing groupwork by constant communication. The use of electronic devices such as tablets and other technologies can be an extra motivation to reinforce positive predisposition of students towards the subject contents, especially when courses are mostly developed via lectures.

Group dynamizers or routine breakers constitute another innovation line at university level (Muñoz-Luna, 2014), at least in the University of Málaga where many courses are still based on lectures. In this case, making the class more dynamic is the primary objective, which is achieved by interrupting the lesson periodically with another task, normally shorter. Such interruption is a partial or total break with regards to the previous activity. This implies proposing sudden changes in the lesson environment (Styles, 2005) employing visual and aural stimuli, and even physical involvement from the students, changing places, etc. More specifically, the aim is to effectively increase learners' attention span, what has also been demonstrated by Hull (1984).

Moreover, significant effort by teachers is directed towards learning-by-doing activities. With these strategies, students learn in a more meaningful manner since they experiment with and recreate the concepts they are learning. Real-life scenarios are simulated in realistic laboratory contexts so that conditions are appropriate. Thus, several experiments could be implemented (Jurado-Navas, Muñoz-Luna \& Taillefer de Haya, 2014).

The employment of virtual platforms and portfolio (Biggs \& Tang, 2011) constitutes another means of innovation in university teaching by developing critical and reflexive skills in students, and not only memoristic learning. In this case, Mahara portfolio (https://mahara.org/) has been employed by the subjects of this experience. We must remark that this portfolio facility started only a few years ago (2010) in our university, and today it is almost only known in the Faculty of Education.

Finally, the creation of software and telematic tools specifically designed for solving concrete needs and problems are innovation strategies to support the teaching task (Muñoz-Luna, Jurado-Navas \& Taillefer de Haya, 2014). As a result, collaborative learning environments emerge.

\subsection{Constructivism, Social Constructivism and Situated Learning}

Scrum methodology is rooted in constructivism, which at the same time is based in the theories of Piaget (1977), Ausubel (1981), Bruner (1961) and Vygotsky (2012), and defends the fact that knowledge is produced when an individual is able to create meanings from their own experiences. Constructivism favours the use of only what interests the individual in order to construct new learning and more meaningful knowledge. In this manner, if what is newly acquired is considered relevant, it is incorporated and stored in our memory. As Ausubel indicated, we need 
predisposed students for meaningful learning, that is, students who feel interested and motivated by the learning process. Such intrinsic motivation is one of the objectives to be achieved by the scrum methodology. In this respect, and as we show in this paper, the intrinsic motivation is achieved by taking into account the student's interests and by the applicability of the knowledge in a real context.

According to Martín Ortega et al. (1995), to experience interest for something implies to know what is involved and to feel that a particular need is covered. On the contrary, if the purpose of a task is unknown, the student will not be able to relate such a task with its implications, nor with other areas of knowledge, nor with their own personal needs and interests. In such a constructivist approach, the intervention of context is crucial. Context determines and surrounds knowledge, and therefore it has an impact on what we store in our memory. The context surroudning each individual is also based on the previous experiences of the person in question.

Teachers, on their part, also play an important role in a constructivist scenario. They are mediators who provide support to students by helping them to think and to promote their autonomy and self-initiative (Herrera Capita, 2009). In fact, teachers must investigate about students' assimilation of contents before sharing their own understanding of those concepts. Finally, constructivist teachers promote critical and reflexive attitudes among their students by facilitating appropriate cultural interactions to make their learning meaningful. Bruner (1988) perceived development theories as dependent on culture.

The theory of social constructivism initiated by Lev Vygotsky includes the social factor in the construction of knowledge, and social relations are added to the individual relation with the environment. New knowledge is built upon individual schemes in relation to the schemes generated by surrounding individuals. This theory radically differs from Piaget's, for whom the acquisition of new knowledge is produced only when cognitive conflicts are solved. The key difference does not lie in cognitive conflicts. It rests in individualistic versus group dynamics in knowledge construction.

Finally, situated learning (Lave \& Wenger, 1991; Niemeyer, 2006) proves how the acquisition of competences as a result of learning is not the consolidation of better or worse understanding and skills, but the possibility of active participation in collaborative activities. In this manner, the social dimension of learning is situated before the individual dimension. Opportunities and possibilities of participation become the main criteria for educative success in a social context; we can say that it is a social theory of learning. Consequently, the process of situated learning will occur in those situations in which all individuals share a common objective to implement an activity wich, additionally, they all identify as significant for their learning. These activities are as similar as possible as real scenarios where individuals will have to develop their professional careers.

\subsection{Project Based Learning}

Social constructivism is characterised by social interaction which generates learning. One of the ways to achieve this is by means of academic projects. Project based learning (PBL) is rooted in the theories of Vygotsky, Bruner and Piaget, claiming that the construction of learning is the result of cooperative work and collaboration among students. In this manner, practice is close to reality, in which there is interaction with context. Finally, on the basis of action and experimentation, students learn. Furthermore, learning which is based on projects presents a series of conflict-solving opportunities to learners to which they have to provide an answer.

In order for a project to be appropriate, it must arise from a real need, a real problema. Only in this manner will it be meaningful for students. The project must be planned, and this is a challenge that students themselves should asume so that their learning experience is more intense. Such planning must include everything that is to be done as well as the necessary steps to achieve it. In addition, there must be a research space where to interact with their environment and with other information sources. Consequently, the final result will be a real product that can be observed, heard and touched. González Álvarez (2012) defines a project of this type very clearly: "it is a series of learning experiences that students execute through scheduled activities in order to obtain a concrete product and give solutions to a real problem."

Markham (2011) and Woods, Felder, García \& Stice. (2000) expose the principles upon which project based learning stands, with a particular attention to higher education classroom challenges. The achievement of the proposed project implies the learning of technical concepts, specific skills, competences and attitudes. The previously mentioned authors' principles, together with Aliane, Fernández \& Díez's (2013) more recent ones, can be summarised as follows:

- PBL occurs in a realistic environment. This circumstance helps students to establish a better relationship between theoretical contents of a particular subject and other subjects, mainly, with the real world that they 
will face once they finish their university degrees. Theoretical concepts are better learned in practical environments.

- New contents and information are acquired through self-directed learning. Students are expected to learn from real world knowledge and from the accummulation of experience by their own study and research.

- Students perform an active role in the project. Moreover, they are who establish their own learning rhythm and learning depth.

- $\quad$ PBL is aimed at improving learners motivation. Therefore, this learning methodology could be employed to improve academic achievement and study persistence.

- PBL is closely related to groupwork, planning, communication strategies and stimulation of creativity from the group members.

Group size should be reduced. In fact, Exley and Dennick (2007) recommend that the number of members in each group should be comprised between five and eight, what favours student self-management of possible conflicts arising among them, and their feeling responsible for achieving the proposed objectives. This assumed responsibility by all members of the group increases motivation for task achievement while members acquire a real and strong commitment for their colleagues.

PBL in the form of scrum methodology originated in the industrial sector, more specifically, in Japanese companies such as Toyota (Poppendieck, 2005) and Honda (Humphrey, 1996). Both multinationals are believed to be pioneers in the application of Takeuchi and Nonaka's principles detailed in (Takeuchi \& Nonaka, 1986). Later on, all the previous authors' ideas (Poppendieck and Humprhrey's ones) have been evolving with new contributions from other international companies as Google, Yahoo, British Telecom, Siemens and Ericsson.

In the transfer of these industrial ideas to the academic scene, scrum elements have recently been employed to improve groupwork in academic research (Hicks \& Foster, 2010). Thus, Hicks and Foster (2010) report how daily short meetings reporting results can actually increase $\mathrm{PhD}$ students' interaction among themselves and with tutors and research group members. A more flexible and efficient work dynamics was also created and oriented towards the desired results.

Within this scrum framework, a project development is conceived as a succession of short work cycles named sprints (two-three weeks each). After each sprint, a functional product is submitted in accordance with partial objectives established. The cooperation and engagement of all group members is crucial for multidisciplinary results and meaningful learning..

\section{Research Methodology}

\subsection{Ethical Considerations}

As commented above, ethical aspects were considered throughout this study. In accordance with the Code of Ethics and Conduct (BPS, 2006), the aim of the research and interview method was explained to the participants and the informed consent was obtained from them prior to the beginning of this study. Participants were informed in the classroom about that fact previous to start the experience with some explanatory talks about the scrum methodology. There an introductory document was delivered summarizing the scrum methodology and including a final statement that literally said: "The Scrum project is part of a research project conducted by Professor Antonio Jurado-Navas under the Department of Teaching and Scholastic Organization. All students who take part in this project consent to participate in the research conducted by Professor Jurado-Navas." Confidentiality and privacy was completely guaranteed. The current study is made in a qualitative manner (case study) and no real names nor other personal affiliations were provided through this manuscript.

Furthermore, the research was approved by the vice chancellor of the University of Málaga, former Dean of the Faculty of Education (when the research was designed and performed he was the Dean of the Faculty of Education in the University of Málaga). Not only the research and the methodology was approved but he monitored all the steps during the research and, at the end, the whole project (including the ethical component) was assessed by a board of examiners.

\subsection{Context}

This paper aims to understand in depth what occurs at the university classroom when an alternative teaching methodology is introduced for the first time. In this case, scrum methodology was implemented in a group of undergraduate students of Humanities once our research methodology was approved by the Dean of the Faculty of 
Education at the University of Málaga. In particular, the methodology itself, the study and the results derived were presented in oral defense as the Master Thesis dissertation of one of the authors for the Master Degree in Policies and Practices of Innovation in Teaching, awarded with Honours. Students were informed about this research before starting the experience with some explanatory talks about the scrum methodology and the research project underlying that experience and they gave oral consent to participate in this study. In addition, an introductory document was delivered in one of those explanatory talks summarizing the process involving the scrum methodology and including a final statement that literally said: "The Scrum project is part of a research project conducted by Professor Antonio Jurado-Navas under the Department of Teaching and Scholastic Organization. All students who take part in this project consent to participate in the research conducted by Professor Jurado-Navas."

The starting project proposed by the teacher was gradually fragmented by the students in each group after consensus. In such fragmentation, partial objectives were determined for the following two weeks. Each group (seven groups in total) was self-managed and they provided answers to the proposed topic by means of functional submissions which responded to the group objectives. Every two weeks some results were presented to the teacher by each of the groups. Together with their submissions, each group included a detailed description of the group meetings and the members' roles (the scrum master, basically, whose responsibilities will be detailed below) during those two weeks. They also added their own personal reflections on how everything went by.

This qualitative piece of research is structured as a case study. It was implemented in the department of English Philology at the University of Málaga (in the South of Spain). The involved students were enrolled in the compulsory course of Advanced English Language in the degree of English Studies. As an optional activity, students had to develop a project during the semester. Their submission would be worth $20 \%$ of their final mark. Otherwise, for those students who decided not to participate, the final exam would represent the $100 \%$ of their final mark. Such process of work was documented and supported by online platform Mahara.

The subject in which this observation took place is a compulsory course with a significantly high theoretical content; it is considered the basis for future linguistic subjects in the degree. Contents are related to a generative perspective and analysis of the English grammar. In addition, the number of females and males in the degree is significantly unbalanced (90\% females over 10\% males). All student ages ranged between 21 and 25 years, and all of them were new in the subject, being $10 \%$ of the group students who had previously been enrolled in the subject. Student mother tongue was Spanish, and they had between B1 and B2 English language, with the exception of a few students whose English level was higher. In addition, a small group of Erasmus students took part of the student body of this course. They proceeded from different countries: Ukraine, Romania and Italy; they also participated in the project.

In the adaptation of scrum methodology to the educative context, these are the roles that appear in the process (Jurado-Navas, Muñoz Luna \& Taillefer de Haya, 2014):

- Product owner: this is the role performed by the teacher, who is the expert who knows the product (final outcome) that is to be developed from the project topic. The product owner proposes a topic to be worked by the students. Such topic must be something open and flexible in the student context according with the learning objectives of the course, but also taking into account the student's interests and the applicability in a real context. The topic description should be short, just one or two lines, just to have a basic idea of the project to be developed. The main functions of the product owner are: to decide what to build, to be accesible for all the students, to validate submissions after each sprint and to establish priorities.

- Scrum master: this is a role performed by students, who are facilitators in each team. The scrum master is responsible for meeting calls during each sprint, and they write the meeting proceedings in the portfolio. The scrum master is also the link between the group and the teacher when it is needed. In our implemented experience, the role of the scrum master has rotated among the different group members. The main functions of the scrum master are: to facilitate communication between group members and teacher, to have a self-managed team, to report all important notifications in the portfolio, to plan and schedule meetings during each sprint.

- Scrum team: it is formed by all the students in each team, including the scrum master. A scrum team usually has from 4 to 9 members and it develops the proposed project topic with the aim of submitting a concrete product. All members in the scrum team are aware of the other members' tasks and advances. In this manner, the team works cohesively and in self-management.

Finally, there are other features and events which are typical in scrum methodology. There are daily stand-up meetings, in which the uncomfortable condition of being standing up facilitates agility shortness. At least twice a 
week (the course was organized in two sessions per week), the team held a stand-up meeting so that everyone in the team can know the current state of the project and the members workload. The duration of each stand-up meeting was between 6 and 8 minutes. The typical questions to be answered in such meetings are: 1) "what have you done so far?" 2) "Have you found any obstacle in the process?" 3) "What are you planning to do unil our next meeting?" Secondly, there are different tasks to be developed during each sprint. In this case, each task should be short and never taking longer than 2 hours of individual work. That was our proposal considering the number of credits of the course (6 ECTS) and the weight this scrum project constituted in the final mark (30\%). Thus if the scrum master considers that a task should take longer, the task must be divided into shorter ones.

As mentioned above, this scrum-based learning experience was applied during the first term of the 2014/2015 academic year. Concretely, the deadlines associated to the four sprints composing this experience were including in the following table:

Table 1. Start and end dates for the four scheduled sprints

\begin{tabular}{lrr}
\hline Sprint & \multicolumn{1}{c}{ Start dat } & \multicolumn{1}{c}{ End date } \\
\hline Sprint 1 & 17 November 2014 & 29 November 2014 \\
Sprint 2 & 1 December 2014 & 13 December 2014 \\
Sprint 3 & 15 December 2014 & 9 January 2015 \\
Sprint 4 & 12 January 2015 & 23 January 2015
\end{tabular}

To summarise, this scrum methodology consists on creating an incremental framework for projects, where a project can be understood as any complex activity or task developed and achieved within the course. Scrum structures in a course develop in work cycles called sprints. In theory, these iterations must not last more than one month each, and must be realised in a consecutive manner without pause. The sprints are timeboxed, finishing on a specific date whether the work has been completed or not, and are never extended in time. With such fixed working schedule, students become acquainted with timely submissions and work cycles. Figure 1 shows how the scrum based learning method is organized. In our experience, we have divided the course in four different sprints, each one with 2-week duration, whereas the daily meeting happened twice or three times per week (the course were scheduled in two different sessions per week). The sprint always started by an initial meeting where the group decides the objectives and milestones for that current sprint on their own, dividing this objectives in short tasks to be assigned to the different members in the team. After the different iterations (daily scrum meetings and individual work to be committed every two consecutive stand-up meetings), the current sprint finishes with a double meeting: the review and the retrospective meetings. In the first one, the entire group collaborates on what to do next, so that the review meeting provides valuable input to subsequent sprint planning. In this respect, one objective in this review meeting is focused on how the team can use the feedback provided by the teacher in the next sprint to approach a bit more (and with more efficiency) to the final solution for the project defined by the teacher in the beginning of the process. Meanwhile, in the retrospective meeting, the team inspect how the last sprint went with regards to people, relationships, process, and tools; in this sense, students reflect about how the team has worked, how their individual work (as a member of the group) has contributed to achieve the objectives selected in that current sprint. If the sprint about to finish is the last one, then the team must deliver the final solution; otherwise, the team must deliver a functional solution, showing an increment with respect to the product delivered in the previous sprint. 


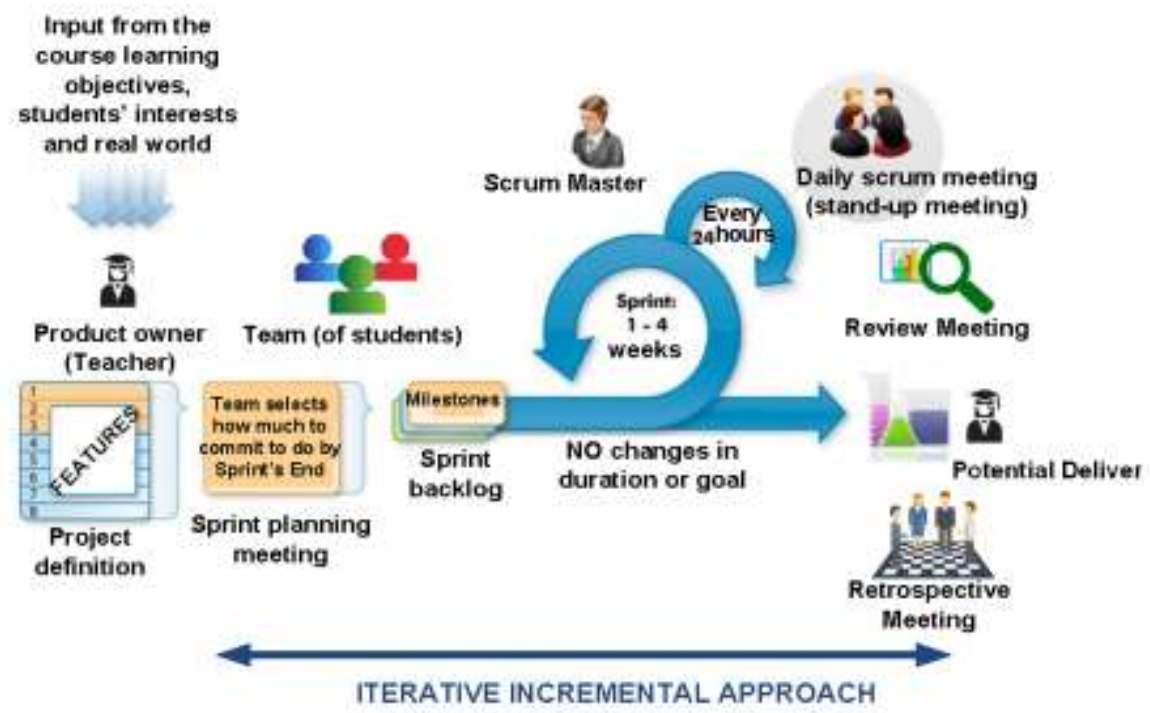

Figure 1. Stages and features in a scrum methodology.

\subsection{Research Objectives}

The main aim of this paper is to reflect on the educative value of an alternative methodology, the so-called scrum methodology. Scrum methodology seeks to foster student participation in self-organised working groups in which interaction and communication are fluently among their members and with the teacher. In this regard, groupwork is fostered, giving students the opportunity to satisfy their needs by creating a realistic working environment. In this manner, the university is not perceived as a completely independent entity, separated from reality, but precisely the reverse: it is an institution which is permanently in contact with its surrounding reality, developing a process of teaching and learning within certain contexts which will be the precursors to the ones students will find after graduating.

Scrum methodology expects to develop a practise groupwork dynamics in which students learn to manage their time and resources, adapting themselves to unpredicted changes. Fluently communication processes and continuous interactions are the means to achieve the previously set objectives, internalised by all the members of the group. Students hold a series of periodic meetings with the aim of advancing in the project; they know what they have done and who did what, and they share and discuss future roles and tasks in the project. The scrum experience in this case has been implemented in an area of expertise related to Humanities and not to Engineering, where the origins of this technique are.

\subsection{Research methodology: Scrum Projects}

The project starts with a proposal from the teacher, an open topic that students should develop. This first meeting where the teacher defines the project, and explains the different stages, steps and roles involving the scrum methodology was called Sprint 0 . The election of the topic is conditioned by the subject contents and its learning objectives, but it is important that the topic is open and flexible enough for students to develop their ideas freely. In this case, the proposed project in our experience was presented as follows: "How can generative grammar improve online automatic translators?"

All stand-up meeting reports and outcomes were compiled in the online portfolio Mahara, which became the working tool for the scrum teams. The project was designed for 8 weeks, having 4 sprints of 2 weeks each, as detailed above. After each sprint, the groups submitted what they had, with the aim of submitting a finalised product at the end of the project. As described above, each sprint included several stand-up meetings of about 6-7 minutes; these were also considered routine breakers during the class (Muñoz-Luna, 2014), becoming a good activity to include in any session with any teaching method (lectures, dialogue-based learning, study cases, etc.)

\subsection{Research Methodology: Observations and Interviews of A Case Study}

The research methodology that has been followed here is a case study. Case studies are process of indagation characterised by a detailed, comprehensive, systematic and deep analysis of social units or specific educative entities (Yin, 1989; Rodríguez Gómez, Gil Flores \& García Jiménez, 1996; Álvarez-Gayou, 2003). 
Several interviews were made with student participants throughout different moments in the subject: a first set of interviews at the middle of the scrum project experience, and a second and final set of interviews at the end of it. The transcriptions associated to those interviews (in Spanish) were provided as a supporting information file. We must comment that all the names included in those transcriptions are completely fictitious except the one referring the teacher, Prof. Rosa Muñoz-Luna, one of the authors in this paper, and consenting to include her real name in those documents.

The following table illustrates the different stages and research insturments with which results were analysed:

Table 2. Research instruments used during the experience to collect data to be analyzed.

\begin{tabular}{|c|c|c|}
\hline Tool & Activity & Expected outcomes \\
\hline Interviews & $\begin{array}{l}\text { Seven interviews carried out in five sessions. Each } \\
\text { interview lasts for } 20-30 \text { minutes. } \\
\text { - Two group interviews, one in the middle } \\
\text { of the experience, and another one at } \\
\text { the end. } \\
\text { - An individual interview to the best } \\
\text { student in the group } \\
\text { - An interview to the group teacher }\end{array}$ & $\begin{array}{l}\text { Specific aspects of each target group in the } \\
\text { research process: students and teacher. }\end{array}$ \\
\hline $\begin{array}{l}\text { Evaluation } \\
\text { questionnaire }\end{array}$ & $\begin{array}{l}\text { A set of } 11 \text { questions following a five-level Likert } \\
\text { scale to be answered in an anonymous way once }\end{array}$ & $\begin{array}{l}\text { To obtain a rating scale in different features } \\
\text { related to the experience. }\end{array}$ \\
\hline
\end{tabular}

\section{Results}

A specific page in Mahara portfolio was created so that all projects could be visible there. Mahara was the place where participants would write their reports and present their outcomes:

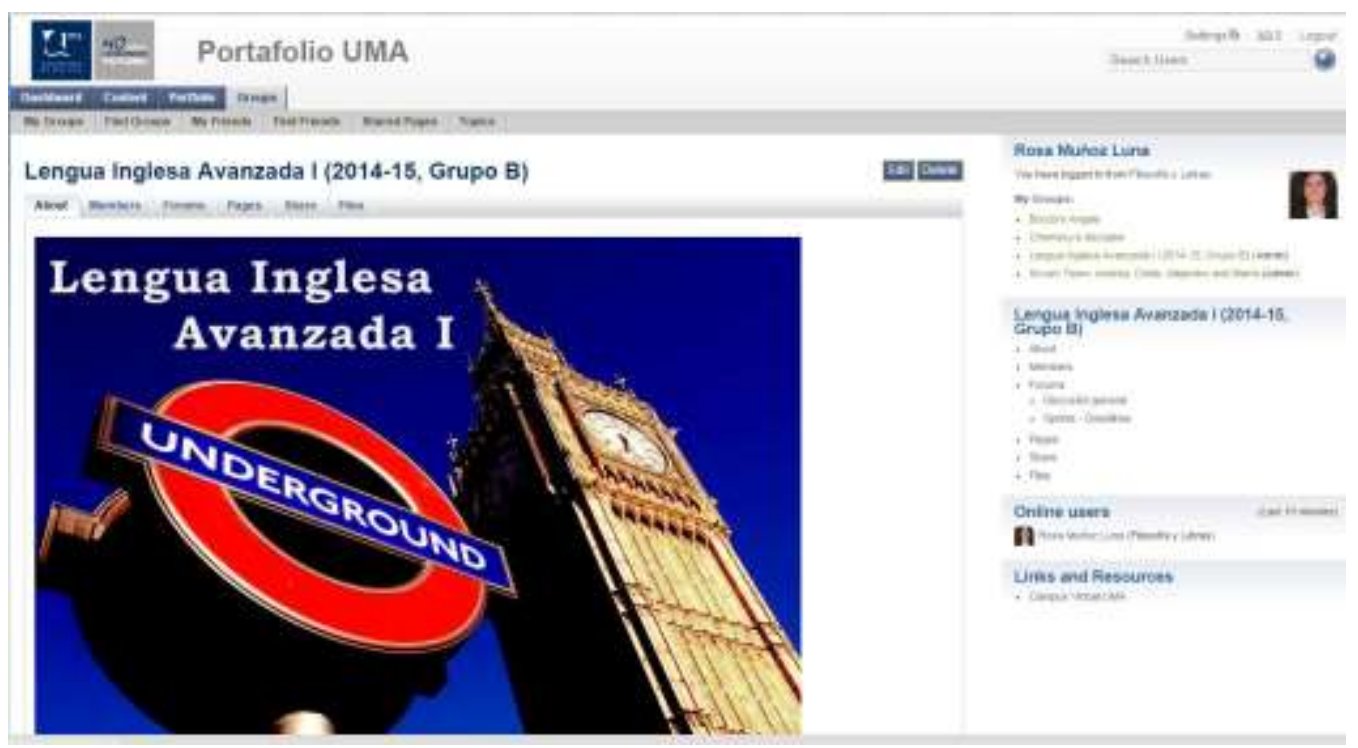

Figure 2. Appearance of the course in Mahara platform. 
The starting point results obtained in this research process were not flattering. The opinions gathered from the first student interviews revealed their preferences towards individual work:

- "I prefer individual work more" (Student 1).

- $\quad$ "Well, it depends on the subject. If there is a presentation to do in front of the class, then I prefer groupwork. Otherwise, I prefer individual work" (Student 2).

- $\quad$ "The poblem with groupwork is the lack of coordination among group members. There is always somebody who does not do what they should" (Student 1).

As we can see, the starting point was difficult and motivating at the same time (motivating because the student's interests are taken into account and the students can check the applicability of the knowledge in a real context).

The teacher herself exposed her initial concerns regarding evaluation and the teaching of certain contents. Scrum philosophy implies leaving students do the work on their own, by themselves, and the teacher was unsure about to what extent the contents would be covered:

"We have several difficulties, don't we? Evaluation and contents. How do I evaluate this? How do students evaluate themselves? Which numerical mark will they obtain at the end? This is what students are also very worried about. And on the other hand: will I be able to teach all I want to teach? If students have total freedom then teachers intervene very little..." (Teacher).

After the first sprint, Groups 1 and 2 shared, respectively, the following posts in their sprint report:

"We were at the beginning of the project and that means that we were uncertain about many things. We didn't know anything about automatic translators nor their relaionship with generativism. Honestly, we felt lost and most of the time was spent to solve questions. Now we think that this experience is very interesting and challenging." (Group 1).

"After all the problems we had at the beginning regarding grop dynamics and scrum methodology (we didn't understand the procedure very well), we have started to work on the project." (Group 2).

During the process, results turned more positive. The teacher stated that students needed from 10 days to two weeks to understand scrum procedures. Group 4 explained the development of their groupwork during the scrum experience:

"All group members have carried out their tasks responsibly and we have all shared our progress during the stand-up meetings. We first started looking for ideas in books and papers on the Internet, and then work was divided into different tasks. We reached our objectives by covering main issues first, and then delimiting what we needed. Finally, we also know that we could improve our organising skills." (Group 4).

All the groups could understand, from the very beginning that decisions were made in team. Consequently, the election of the topic must be one every member likes; they also have to agree on the role assignment and task procedure in the group. Such feeling of cooperation is expressed by a student during an interview:

"Within the members of the group there were some people who, for example, were better in syntax, right? So if anyone else got stuck at some point, those people maybe tried to give them what they needed." (Student).

One of the initial strengths of scrum methodology is giving importance to the communication process, especially within the members of the same group, and between groups and teacher, who acts as product owner. Communication is one of the keys for scrum success. The teacher corroborates this claim as she felt fluid and constant communication allowed her to be an active participant in each group:

"Regarding my communication with them, it was very good. Well, I think I have always had good communication with my students, but no doubt it improved. They made me participant of what they were doing, their progress and their discoveries. They know me for being a teacher who does things differently in the classroom, and so every method I use tend to call their attention" (Teacher).

Teacher's feedback was provided in different manners: sometimes it was in the classroom, during stand-up meetings, and in other occasions it was through comments on Mahara platform, holding an active attitude and involvement in each group. These are some examples of Mahara feedback by the teacher during the experience: 


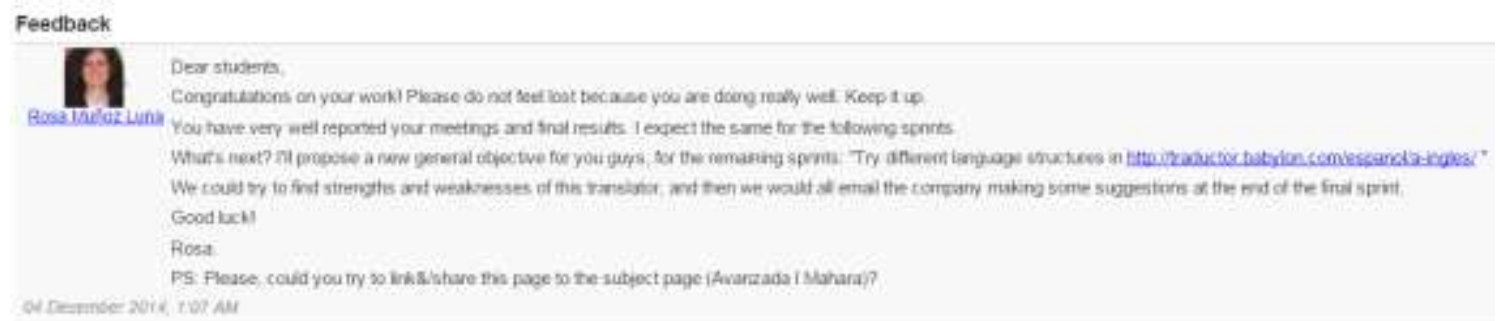

Figure 3. Example of feedback given by the teacher to Group 1.

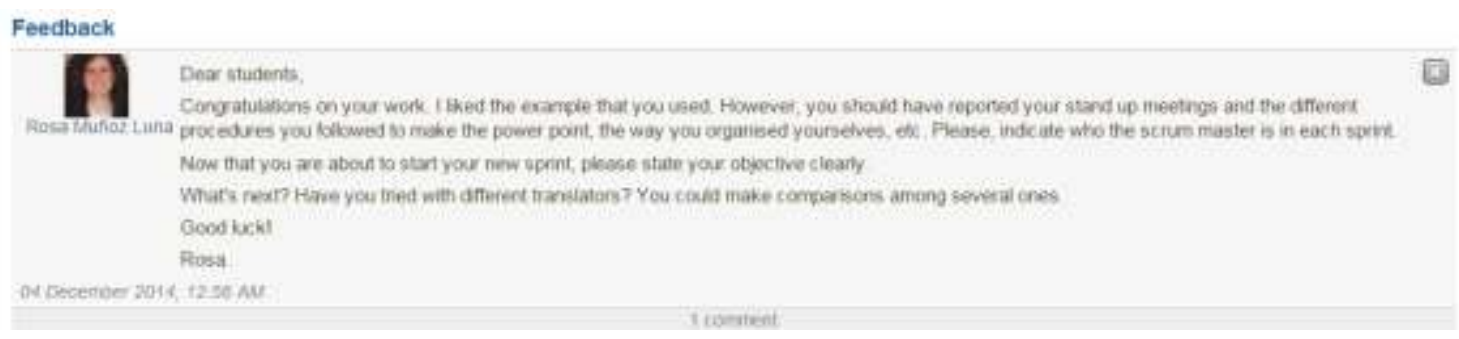

Figure 4. Example of feedback given by the teacher to Group 2.

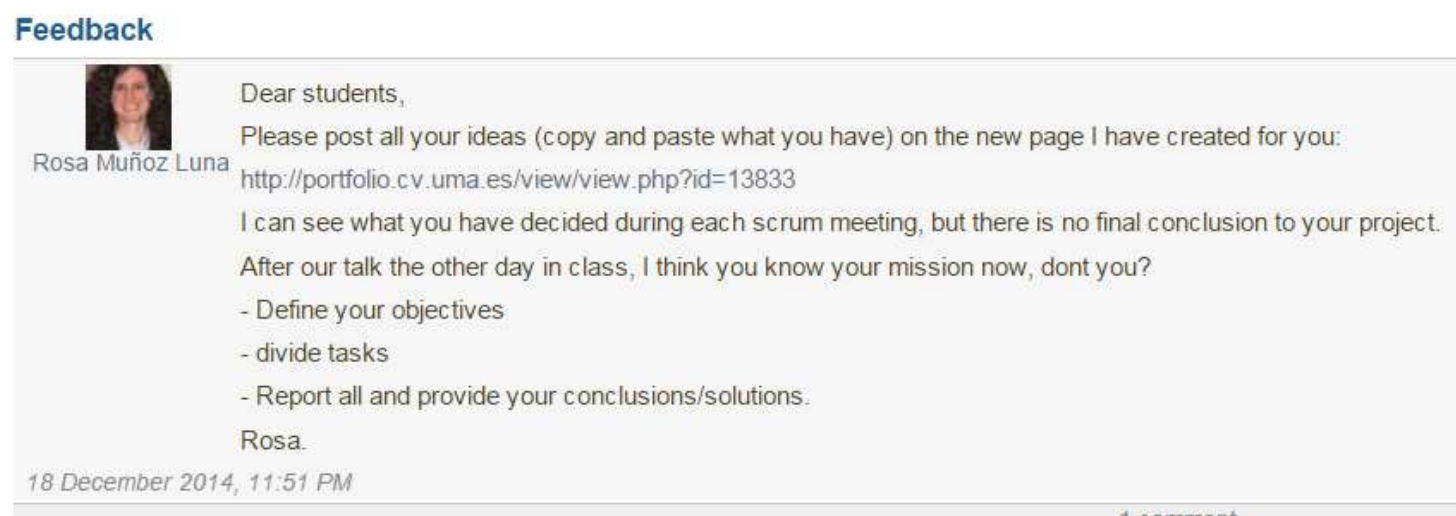

Figure 5. Example of feedback given by the teacher to Group 3.

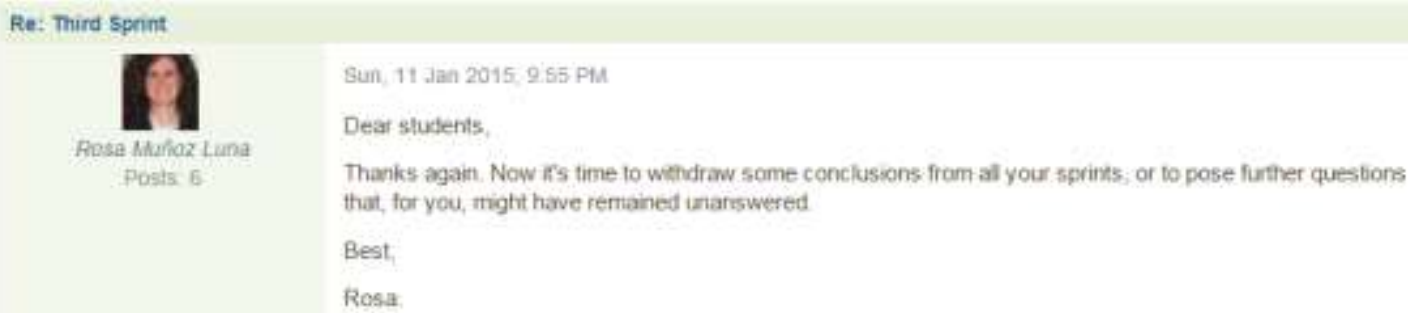
Posts: 6 :

Figure 6. Example of feedback given by the teacher to Group 4.

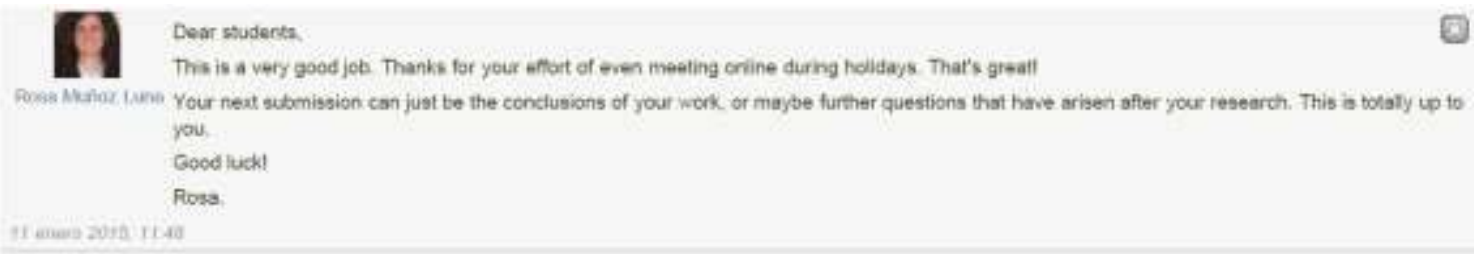

Figure 7. Example of feedback given by the teacher to Group 6. 


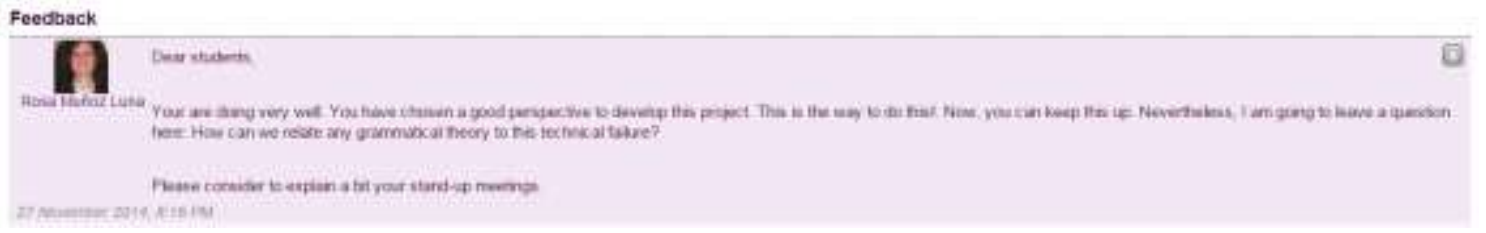

Figure 8. Example of feedback given by the teacher to Group 7.

As we can see in the examples above, there is positive feedback in which the teacher suggests the analysis of something in particular to the group or she leads the group towards an aim in particular. Moreover, in Groups 2, 3 and 4, the teacher provides more specific instructions for them to follow a scrum methodology, or she asks them to share their progress via the subject virtual platform. In addition, the teacher employs this feedback to revise previous comments already given to students during their stand-up meetings and at the end of their sprints, as one student highlights:

"The teacher points out our errors, and then includes some comments. Firstly, she congratulates you. Always. She always says congratulations first. And then she goes like I have a questions, or a comment, or so" (Student).

\section{Discussion}

With the constant feedback from the teacher, both in the classroom (review meetings, especially) and online, the level of self-efficacy in students and their need to perform better increases. Students feel they have a commitment to follow the teacher's instructions and to achieve the course aims. According to the results obtained in the observations and document analysis, these are the basic principles that are present in scrum methodology:

- Students act freely

- $\quad$ Project ideas are divided into smaller projects (sprints). Each sprint contains a number to objectives to achieve, and a number of tasks to be perfomed by each group member

- $\quad$ Frequent follow up meetings to know the state of the art

- $\quad$ All the freedom that students have to perform their own projects freely is compensated with a strict schedule for submissions. Deadlines in sprint tasks are necessary for commitment and also for efficiency

- $\quad$ The combination of the three previous principles allows students to feel positive stress (Selye, 1974). This is also the consequence of student interaction, resolution of small tasks, and the submission of tasks on time

- The writing of a portfolio with all the details of the progress, task división, who did what, etc.

Reflections offered by Group 6 during their second sprint, for instance, illustrate very clearly the evolution of the group and how they provided feedback to each other, what was positive when they had to solve problems and be aware of their tasks. These are some excerpts:

1st December 2014

We plan to develop the topic this week, looking for more information into different but related fields. We will meet tomorrow to discuss how to get the information and how we will present it.

2nd December 2014

Since one of us had problems in finding the corresponding information (Use of other gramatical theories), we have decided to change her topic (Development of other theories). With this change it will be easier for her to fin data as the topic is broader. Our second stand-up meeting will take place on Thursday.

12th December 2014

Although at the beginning of the week we thought we would not reach our aim, we finally succeeded and have learned many interesting things which we had not analysed before. Working in group is a pleasure!

As we can see, human values such as empathy and cooperation are practised in scrum methodology. All group members feel committed to a common purpose; they also feel their effort is something they share. 
The possibility of having each group working on their own ideas fosters self-management within the group. All group members try to achieve a common objective. Critical thinking and personal reflections are key in each sprint, where members know more about themselves and about their colleagues. As Group 2 members stated, scrum methodology has revealed some skills hidden for them until then:

"Yes. Honestly I've discovered my own analysis skills, and then I say let's compare this, and maybe I'm right, maybe I'm not so traditional in my thinking. I think I'm more innovative than I thought" (Group 2).

Not all groups succeeded, and the reason could be the absence of obligatoriness. The optional character of the experience made some group fail. Participating in the scrum projects meant improving your final mark in the subject up to $30 \%$, but not all the students decided to tale part in them. In addition, there is an important challenge for the teachers: to early detect potential difficulties, or very ambitious objectives impossible to accomplish during one sprint or even during the whole experience. Both causes may make Group 5 fail in this experience, with especial relevance to the first one since one of their members hardly ever had time to dedicate to the team (her preferences and interests were others completely different, especially knowing that this experience was not mandatory to pass the course).

This aspect can be the reason for the lack of participation and motivation for students. For some students, the traditional evaluation was more appropriate for them, and they were unwilling to participate. In some cases, some group members did not participate in a group, and so the rest of the members in the group abandoned the project. In some other cases, the teacher could have been quicker in identifying the problema or in providing more accurate feedback before. That might have impeded the development of successful projects in some of the groups.

As commented, the qualitative research was performed via ecological observations, interviews and analysis of documents. From it, we have derived the following pattern of behavior in the students participating in this scrum experience:

\section{a) Non-flattering starting point}

Most of the student's opinions were negative regarding the work in groups. "I prefer personal work", or "it depends on the course, but if it is a matter of a public presentation, then I prefer to work in group, otherwise individually", were some of the responses given by Group 7 regarding groupwork.

b) Fear and stress at the beginning

That feeling was shared by the students and also by the teacher. The beginning of something new, different from what you are used to doing, is always difficult and causes doubts and fears. With this experience we have substituted the fixed guidelines governing a classic course by a laissez-faire learning. The teacher herself states:

"Difficulties, I think they are the ones shared among teachers regarding to the groupwork itself, on the one hand the students' assessment, and on the other one, the proper contents of the course. Then, evaluation, how can I assess this?, how can students evaluate themselves?, what final mark are they going to get?. Because at the end it seems that this particular fact is the students' main concern and what stresses them out the most, right? And then on the other hand, the content: will I have time enough to give all I want to teach? Will they divert much about the topic? Because I noticed this methodology implies at the end freedom for the student, almost absolute freedom, right?, then where the teacher takes little part and, certainly, in the subject where I introduced this scrum methodology, which was a little more theoretical and technical, I was afraid of leaving important things unsaid" (Teacher)

Similar thoughts were found in the students. For instance, Group 3 reflected through Mahara at the end of the first sprint:

"We were in the very first stage of the Project and that thing implies many doubts, mainly on what we would need and on how we could obtain it. We had no idea about automatic translators neither on how the generativism could be applied to this specific field so most of our time was spent on trying to clarify our doubts. Honestly, we felt lost without knowing how to proceed with this activity. Nevertheless, it is becoming a really interesting experience since we are facing something new and the entire group is collaborating to accomplish results what, at the same time, it has becomes in something really motivating to follow with the project" (Group 3). 
c) With practice, the dynamics is being progresively understood

We have observed that, on average, all the teams need two weeks (one sprint) to perfectly understand the new dynamics. After such two weeks, all the groups have successfully experimented the three first stages from Tuckman's team development model, namely forming, storming and norming (Tuckman \& Jensen, 1977). Accordingly, boundaries of both interpersonal and task behaviours were identified, and some members in the group arises as leaders. In addition, conflicts and polarizations around interpersonal issues initially acting as resistance to group influence and task requirements were overcome. We have realized that members in every group already accept other viewpoints and a trusting atmosphere has been created in which in-group feeling and cohesiveness develop and in which intimate, personal opinions are expressed. Thus after these two first weeks, all the groups are in the stage labeled as performing. Members of Group 6 expressed through Mahara this situation at the end of the first sprint:

"We will be more relaxed in this upcoming week since we know each other and we already know how to work. We may need some changes but we do not need more time to understand the methodology" (Group 6).

d) Consensus, even in the more complicated decisions, always in support of the common goal

Especially after the first sprint, and as a direct consequence of reaching the stage labeled as performing following Tuckman's model, all the groups were embracing the new situation in which decisions are made after consensus with all their members in a group. Thanks to that, the students feel part of the group, they decide how to rotate the scrum master role (normally, the student with an inherent role of leader used to assume first the role of scrum master), and flexibility is the key factor in this experience. All the members in a group talk and decide what kind of solution they would like to deliver at the end of the project, showing their own interests and background. Taking this latter fact into account, they assign themselves the tasks thought to be included in the current sprint. One of the students in Group 5 stated:

"Well among all the members, some of them in the group had a more solid basis on syntax than others, right? Then, if perhaps someone became blocked in any point, that person always tried to give him what the other was lacking" (Group 5).

e) Communication encouragement through the student's participation, the feedbacks and the interchange of ideas

Communication is one of the pivotal strengths in a scrum-based learning. In fact, it is essential to develop the work with success since the students learn it is really important to know the other members of the group and what they can provide to the final objective; directly related to that point, the students develop the feeling of emphaty, they interchange their opinions and points of view with naturality and that fact encourage themselves to communicate with the teacher via the scrum master (we must remark that the scrum master role was rotated among the different group members changing it every new sprint). Furthermore, communication with the teacher and feedbacks from her is maximized, especially at the end of a sprint, directly in the classroom, by participating in the review meeting, or through Mahara portfolio, a really effective tool to maintain an immediate and permanent communication with all the groups of students. Figures 3-8 show some examples of the feedback provided by the teacher to the different groups.

This permanent communication among students and between the groups and the teacher is essential to detect potencial issues in the first stages of the project, to know in a deep detail the potentialities of the rest of the group and to appreciate even more the work developed by the rest of the members in the group and, of course, your own work, almost equally contributing to the final solution planned by the group to response the topic of the project proposed by the teacher. In this sense, Group 3 commented:

"Yes, I think it's easier. Although you have your own way of doing things, the fact that you are continually sharing and talking and it is always good to know that the other person has their own opinion. This will always bring something good, and we know the consequences of each other's work: leaving some task unfinished, someone who doesn't work on their part, etc. After all, when we meet, I don't have any problems with them, we are doing fine, we talk about pretty much everything: we need this and that and so on, and then we get organized" (Group 3).

For this reason, the scrum master must write on Mahara a brief report of every meeting they have indicating the tasks already done, currently in progress and committed to do. This must be done the same day the meeting was held. In addition, at the end of one sprint, they must share via Mahara their technical advances 
in their project and how they are advancing towards the final solution.

f) Higher degree of self-demand and commitment: more emphaty

From our research, we have observed the students were more engaged with a higher commitment from all the members of any group. They are participating in all the phases of a realistic project (definition of tasks, design, development, implementation, evaluation...) previously personalized to their own interests by the own group, and applying a methodology that they may find when joining the labour market. Under our point of view, the students feel more engaged because:

- They have freedom to choose the best answer for the project (laissez-faire learning).

- The whole project is divided in short mini-projects (sprints) with concrete objectives proposed by the group. The sensation of overcoming new milestones uses to convey an increase in the student's motivation, since they are detecting real advances towards the final objective.

- Constant meetings (stand-up meetings, review and retrospective meetings, or the initial meetings previous to a new sprint) are an asset to monitor the status of every task in progress, and to detect issues and problems in some specific tasks.

- There exist rigid deadlines (every sprint finishes after two weeks and the final solution must be delivered at the end of the fourth sprint). Freedom, continuous increment towards the final solution and strict deadlines can generate a certain positive stress called eustress in the students (Selye, 1974).

- Writing on Mahara portfolio the information concerning all the meetings held by the group allows the students to have a clear picture of the work performed by all the team and how important every member results for the entire group.

g) Improving the self-knowledge D

Biggs and Tagg perfectly summarises this aspect in (Biggs \& Tang, 2011): "Learners learn best when they feel free to move, are trusted and are able to make decisions and take responsibility for their own learningconsistent with clear policies and procedures and with an organized environment for learning".

Self-confidence is also improved in the students because they are completely aware of being able to perform tasks that initially they thought they were capable to do. In this sense, it acts a remarkable positive factor the creation of a trusting environment, and the relaxation produced by the presence of the other members of the team eagered to help when a problem in a task arose. One of the students stated:

"Well... I've realised that I am better than I thought when working in groups. I thought I was... I don't know, this has helped me to see myself, I don't know... like I was able to organise things; if maybe there was a certain moment in which I didn't know what to do, I don't know... I managed better than I thought. And then with my groupmates, well... I've learned from them, mainly those things in which they are better than I am; I've learned who was more capable of solving problems out and more quickly" (Student).

h) Increasing the horizontal perspective

In this learning experience, the students must acquire some learning objectives describing the course. But since it is planned as an open project, completely flexible, students are encouraged to use their previous knowledges from other courses if they may be appropriate for the common goal. The laissez-faire learning including learning by doing and learning by discovering let the students increase their horizontal perspective. The course, "Advanced English Language" is not seen as a completely isolated subject but completely interrelated to the rest of the courses in the degree of English Studies and, in addition, with their future after graduating. "We see what we are learning makes sense" is the answer of one student from Group 3. Others, like Group 2, asked for help for some students from Computer Science because they noticed that the more heterogeneous the team the more enriching the experience and the final outcome.

i) Reflections and retrospections: "I would participate again"

Scrum methodology requires some effort and active implication from the teacher and from the students, and the result is something unexpected and undefined. Each group is free to work and deal with a topic according to their own standards. Teachers have to know how each group is advancing and they have to be constantly providing feedback; this implication from practitioners will make each sprint possible. Hence, all 
(students and teachers) value in a very positive way this experience as a good manner to activate students and to achieve a quality learning environment at university. The widest extended comment at the end of this experience is that "I would participate again". The final reflection from Group 6 and shared on Mahara portfolio summarises this feeling:

"At the beginning of this project, we did not feel really comfortable with the issue. We have never studied before anything about "machine translation". The first week, we were a little bit lost with the organization of the group. But we managed to keep it under check.

As we have mentioned in our diary before, the working atmosphere in our group has been completely motivational for this project. As well as the topic, it has been more and more interesting as we studied it.

As time is concerned, we would have liked to have much more for this project in order to focalize it in a more practical way. We thought that this kind of projects will be more productive for working in a period of an academic course or who knows, maybe for theses and doctorates.

This topic is really interesting for us and absolutely it is reflected on our work. Moreover, it has been a great experience to work with this new project which is Mahara and its new platform. We have learnt to work better as a group, and to feel more implicated within it. And this new way of working, without a shadow of a doubt will facilitate our future plans and give us more ideas to improve our knowledge and be better professionals in our fields" (Group 6).

At the end of the experience, we gave a questionnaire to the participants in this scrum experience so that they can share, in an anonymous way, their impressions. Results are included in Figure 9 on next page, showing that 16 of 28 students answered this survey.

Results are coincident with both the opinions derived by the students in the interviews and with their reflections written in the portfolio. We can remark the increment both in the knowledge of themselves and their own capacities as well as in the knowledge of their groupmates' capacities. Communication and participation are also really well valued. On the contrary, the teaching material was the worst valued item. Some students commented about the complexity of Mahara portfolio, especially at the beginning of the experience. We have observed we need to dedicate more time to explain this platform in more detail for future experiences.

\section{Concluding Remarks}

The present experience based on scrum methodology we have reported through this paper can be considered as a really valuable and effective teaching learning process for today's universities. The effort to find a breaking topic (currently demanded on institutions and companies) and the flexibility, freedom and trust gave to the students can be seen as part of its potential value. Communication is a key factor in the whole process, helping the students to achieve a meaningful learning. In this respect, Mahara portfolio (portfolios in general) plays an essential role reflecting the status of any group, its advances, issues, feelings, relationships, reflections... It helps in a significant way to form an experience where both teaching and assessment can be constructively aligned.

In addition, through this experience, students also develop other soft skills really needed in their professional future: self-confidence, organizational skills, discovering they are able to face with complex projects, ability of working in teams ... In this sense, knowledge, skills and attitudes were improved through this experience.

Flexibility was seen in the different final solutions delivered by the students. Hence, we can cite theoretical works, technical reports submitted to companies developing commercial automatic translators, videos or even software applications.

Regarding the alternative conception of competences (restricted to only three) provided by Pérez Gómez (2012), and directly adapted from the OECD (Organisation for Economic Co-operation and Development) Program Definition and Selection of Competencies (DeSeCo), we have observed that a scrum-based learning experience is able to develop all of them, namely:

a) Capacity of using and communicating the knowledge in a disciplined, critical and creative manner.

b) Capacity of living and coexisting in heterogeneous human groups.

c) Capacity of thinking, living and acting with complete autonomy. 


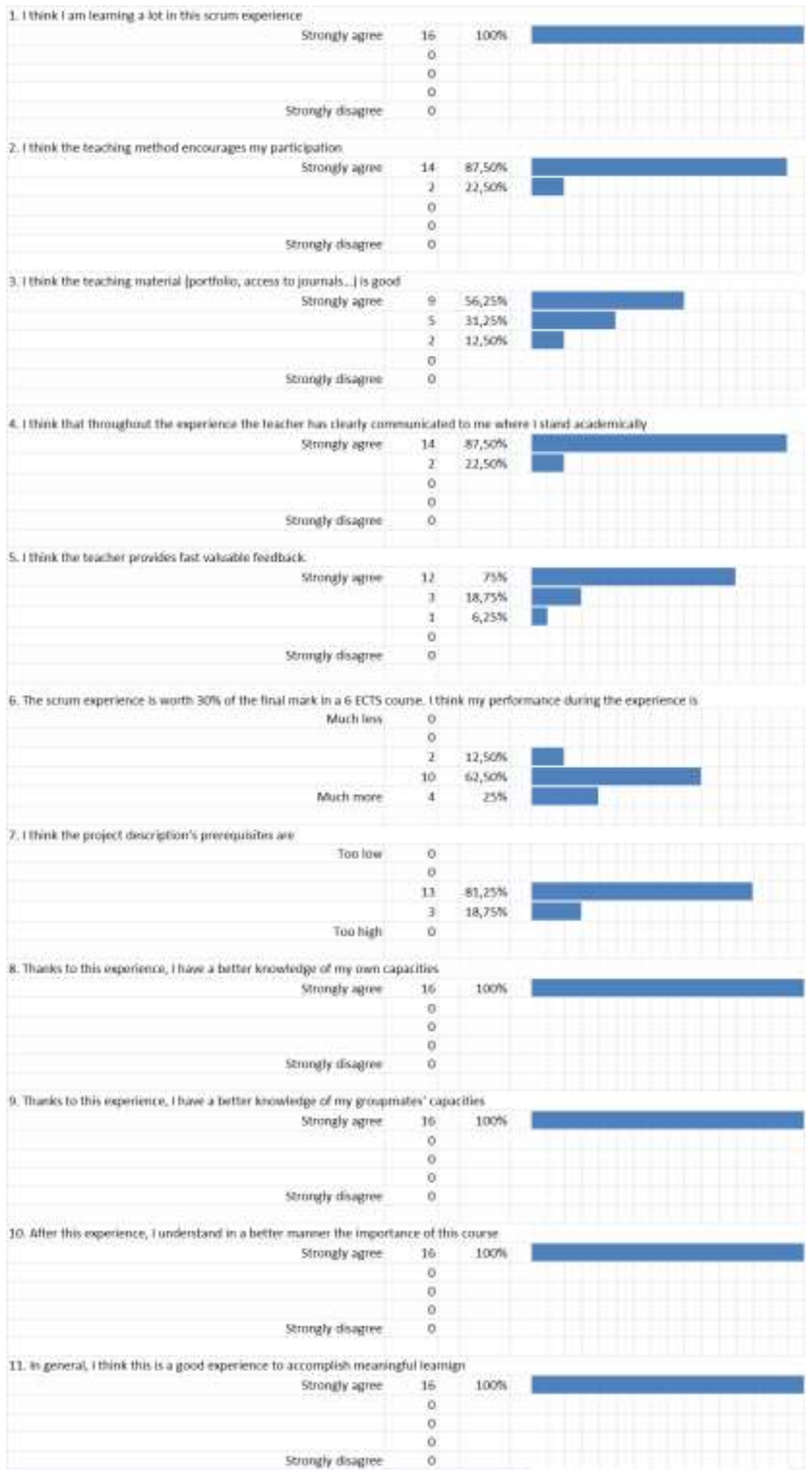

Figure 9. Experience Evaluation Questionnaire. 
So we have described a case of success applying the scrum methodology to a course of English Studies at the University of Málaga. The students, and the teacher, overcoming their initial fears, and assuming an extra effort (compared to lecture sessions or to other classic teaching methods) felt really satisfied to have been part of this process acquiring the course contents in a way that follows their personal choice.

\section{Acknowledgements}

The authors want to give special thanks to all the students participating in this study, and to the reviewers and proofreaders of earlier forms of this paper.

\section{Funding}

This research was partially supported by the University of Málaga, Innovative Education Project PIE 15-76.

\section{References}

Aliane, N, Fernández Andrés J \& Díez, R. (2013). Una experiencia de implantación y evaluación de la metodología de aprendizaje basado en proyectos en los grados en ingeniería industrial. X Jornadas Internacionales de Innovación Universitaria. Villaviciosa de Odón, Madrid.

Álvarez-Gayou JL. (2003). Cómo hacer investigación cualitativa. Fundamentos y metodología. México: Paidos Educador.

Ausubel D. (1981). Psicología educativa. Un punto de vista cognoscitivo. Mexico: Trillas.

Bartolomé, AR. (2004). Blended learning. Conceptos básicos. Pixel-Bit. Revista de Medios y Educación, 23(5), 7-20.

Biggs, J. \& Tang, C. (2011). Teaching for quality learning at University. New York, NY: McGraw Hill.

BPS (British Psychology Society) (2006). Code of ethics and conduct. Retrived Septembert 10, 2016 from http://www.bps.org.uk/the-society/code-of-conduct/code-of-conduct_home.cfm

Bruner, JS. (1961). The act of discovery. Harvard Educational Review, 31(1), 21-32.

Bruner, JS. (1988). Desarrollo cognitivo y educación. Madrid: Morata.

Crompton, H. (2013). A historical overview of mobile learning: Toward learner-centered education. In: Berge ZL, Muilenburg LY, editors. Handbook of mobile learning (pp. 3-14), Florence, KY: Routledge; 2013.

Exley, K.Y. \& Dennick, R. (2007). Enseñanza en pequeños grupos en educación superior. Tutorias, seminarios y otros agrupamientos. Madrid: Narcea Ediciones.

González Álvarez, C.M. (2012). Aplicación del constructivismo social en el aula. Guatemala: Instituto para el Desarrollo y la Innovación Educativa en Educación Bilingüe y Multicultural -IDIE - Organización de Estados Iberoamericanos para la Educación la Ciencia y la Cultura.

Herrera Capita, A.M. (2009). El constructivismo en el aula. Innovación y experiencias educativas, 14(1), 1-10.

Hicks, M. \& Foster, J.S. (2010). Adapting Scrum to Managing a Research Group. College Park, USA, University of Maryland. Available: http://www.cs.umd.edu/ mwh/papers/score.pdf.

Hull, P.V. (1984). Community language learning: is it a method? RELC Journal, 15(2), 15-25. https://doi.org/10.1177/003368828401500202

Humphrey, W.S. (1996). Introduction to the personal software process. New York: Addison Wesley.

Jurado-Navas A, Garrido-Balsells, J.M., Calleja, A., Muñoz-Luna, R., Castillo-Vázquez, M. \& Puerta-Notario, A. (2014). Fluid mechanics: Teaching and learning based on an interactive artificial turbulence generator chamber with adaptive optics. Journal of Materials Education, 36(5-6), 145-160.

Jurado-Navas, A., Muñoz Luna, R. \& Taillefer de Haya, L. (2014). Scrum methodology in university classrooms: bridging the gap between academia and the business world. In: Sánchez Sáinz -Trápaga C, editor. Experiencias en la Adaptación al EEES (pp. 327-335). Madrid: McGraw Hill.

Lave, J. \& Wenger, E. Situated learning - legitimate peripheral participation. Cambridge: Cambridge University Press; 1991.

Markham, T. (2011). Project based learning: a bridge just far enough. Teacher Librarian, 39(2), 38-42.

Martín Ortega, E., Mauri Majós, T., Miras, M., Onrubia Goñi, J., Zabala Vidiella, A., Coll i Salvador, C. et al. (1995). El constructivismo en el aula. Barcelona: Grao. 
Muñoz-Luna, R. (2014). Enhancing language learners' motivation: the use of routine breakers with undergraduates learning English linguistics. Bellaterra Journal of Teaching and Learning Language and Literature, 7(1), 33-51. http://dx.doi.org/10.5565/rev/jt13.513

Muñoz-Luna R., Jurado-Navas, A., Taillefer de Haya, L. (2014). Spectral study with automatic formant extraction to improve non-native pronunciation of English vowels. In: Awrejcewicz J, editor. Computational and Numerical Simulations (pp. 329-343). Rijeka: In-Tech.

Niemeyer, B. (2006). El aprendizaje situado: una oportunidad para escapar del enfoque del déficit. Revista de educación, 341(3), 99-121.

Pérez Gómez, Á. (2012). Educarse en la era digital. Madrid: Siglo XXI.

Piaget, J. (1977). Psicología de la inteligencia. Madrid: Siglo XXI.

Poppendieck, M. (2005). A history of lean: from manufacturing to software development: an agile toolkit. New York: Addison Wesley.

Rodríguez Gómez, G., Gil Flores, J. \& García Jiménez, E. (1996). Metodología de la investigación cualitativa. Málaga: Editorial Aljibe.

Selye, H. (1974). Stress without distress. Philadelphia: J.B. Lippincott Company.

Styles, E. (2005). Attention, perception and memory: an integrated introduction. New York: Psychology Press.

Takeuchi, H., Nonaka, I. (1986). The new product development game. Harvard Business Review, 64(1), 137-146.

Tavangarian, D., Leypold, M., Nölting, K. \& Röser, M. (2004). Is e-learning the solution for individual learning? Journal of e-learning, 2(2), 273-280.

Tuckman, B. \& Jensen, M.A.C. (1977). Stages of small group development revisited. Group and Organizational Studies, 2(4), 419-427.

Vygotsky, L.S. (2012). El desarrollo de los procesos psicológicos superiores. Barcelona: Planeta.

Woods, D.R., Felder, R.M., Garcia, A.R. \& Stice, J.E. (2000). The future of engineering education III. Developing Critical Skills. Chem. Engr. Educ., 34(2), 108-117.

Yin, R. (1989). Case study research. Desing and methods. Londres: Editorial Sage. 